\title{
Highlights misleading the determination of prolonged fever etiology
}

\author{
Natalia Cirlea ${ }^{1 *}$, Daniela Desagă², Emilia Nicoară ${ }^{1,3}$, Alexandru Crişan ${ }^{1,3}$, Alexandra Sima ${ }^{3,4}$, Flaviu Bobb \\ From The 9th Edition of the Scientific Days of the National Institute for Infectious Diseases Prof Dr Matei Bals \\ Bucharest, Romania. 23-25 October 2013
}

\section{Background}

Of the myriad of disorders causing fever of unknown origin, infections have comprised the largest category (25-50\% of cases) explaining frequent misinterpretation of some laboratory results.

\section{Case report}

We present the case of a 34-year-old female with a medical history of fever lasting 1 week before admission to the County Hospital, Clinic of Diabetes, Nutrition and Metabolic Diseases for multiple-localized arthritis (bilateral tibia-tarsus, left radio-carpal, II and III metacarpus-phalanx right hand, right knee), considered reactive arthritis by the rheumatologist; these symptoms occurred a few days after a dental incision. The patient received 1 week antibiotic treatment for positive blood culture with Staphylococcus aureus, without any improvement. The synovial fluid culture revealed Acinetobacter baumannii and the patient was transferred to the Infectious Diseases Clinic II to continue the therapy. The patient followed a further 2-week treatment with a combination of antibiotics, according to the antibiotic test and remediation of dental foci, with decrease in fever and fluctuating evolution of joint inflammatory phenomena. The rheumatologist confirmed the opinion that it was a reactive arthritis. After the expansion of the antibiotic regimen and adding a nonsteroidal anti-inflammatory drug the patient developed acute renal failure that required a decrease in antibiotic dose and the transfer to the Nephrology Department. After the remission of renal failure, the patient underwent an MRI, because of the persistent fever and arthritis, which revealed sacroiliitis. Sacroiliitis proved to be the main cause of the prolonged fever and reactive arthritis.

\footnotetext{
* Correspondence: natalia.cirlea@yahoo.com

'Department of Infectious Diseases II, "Victor Babeş" Clinical Hospital of Infectious Diseases Timişoara, Romania

Full list of author information is available at the end of the article
}

\section{Conclusion}

1. The persistence of fever, despite the appropriate antibiotic association treatment administered according to the antibiotic test for positive cultures, shows that the infection was not the etiology of the prolonged fever, and the presence of Staphylococcus aureus and Acinetobacter baumannii in the cultures was probably a contamination.

2. Sacroiliitis proved to be the main cause of the prolonged fever and reactive arthritis.

\section{Authors' details}

1Department of Infectious Diseases II, "Victor Babeş" Clinical Hospital of Infectious Diseases Timişoara, Romania. 'Department of Infectious Diseases, Municipal Emergency Hospital Timişoara, Romania. "Victor Babeş" University of Medicine and Pharmacy, Timişoara, Romania. ${ }^{4}$ Clinic of Diabetes, Nutrition and Metabolic Diseases, County Emergency Hospital Timişoara, Romania. ${ }^{5}$ Clinic of Nephrology, County Emergency Hospital Timişoara, Romania.

Published: 16 December 2013

doi:10.1186/1471-2334-13-S1-P103

Cite this article as: Cirlea et al:: Highlights misleading the determination of prolonged fever etiology. BMC Infectious Diseases 2013 13(Suppl 1): P103.

Submit your next manuscript to BioMed Central and take full advantage of:

- Convenient online submission

- Thorough peer review

- No space constraints or color figure charges

- Immediate publication on acceptance

- Inclusion in PubMed, CAS, Scopus and Google Scholar

- Research which is freely available for redistribution

Submit your manuscript at Submit your manuscript at
www.biomedcentral.com/submit C Biomed Central 